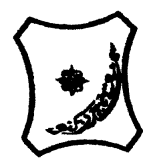

Bayero Journal of Pure and Applied Sciences, 10(1): 658 - 663

ISSN $2006-6996$

\title{
PHYSICOCHEMICAL AND RHEOLOGICAL STUDIES OF Irvingia gabonensis GUM EXUDATES AS SUBSTITUTE TO GUM ARABIC
}

\author{
Sani Mamman Ibrahim, Abdullahi Abdulkadir and Mustapha Bala Muhammed \\ Department of Chemistry, Federal College of Education, Zaria \\ ibrakimikel@gmail.com +2348038060784
}

\section{ABSTRACT}

Irvingia gabonensis (Aubry-Lecomte ex O'Rorke) Baill is a plant found in North Central and North Eastern Nigeria. The plant is used for various purposes such as food and medicine. Physicochemical and rheological studies were carried out on the plant gum exudates. Using standard procedures and the results were compared to that of Acacia senegal (L.) gum exudates. From the results of the physicochemical analysis of Irvingia gabonensis gum exudates it was found out that it has low solubility and high total dissolved solids values in water when compared to Acacia Senegal, odourless, tasteless and with $\mathrm{pH}$ values of 5.42. The viscosity value of the gum exudates were found to decrease with increase in temperature while increases in concentration of the gum exudates were found to increase the viscosity of the gums. And addition of electrolytes solution such as $\mathrm{KCl}, \mathrm{KBr}$ and $\mathrm{AlCl}_{3}$ were found to increase the viscosity of the IG and AS gums solution. The results for the different analysis carried out gives an insight into the possibility of using the plant gum as a replacement for Acacia Senegal gum in applications such as food additive, pharmacological and industrial.

Keywords: Irvingia gabonensis (IG); gum exudates; electrolytes; rheological studies; Acacia Senegal (AS).

\section{INTRODUCTION}

A gum in general, is any water-soluble or water-swellable polysaccharide that is extractable from marine and land plants, or from microorganisms that possess the ability to contribute viscosity or gelling ability to their dispersions (Abu Baker et al., 2007). The most fundamental property of a gum therefore is its water solubility and high viscosity in aqueous dispersions. Among the advantages of natural gums over their synthetic counterparts are their biocompatibility, low cost, low toxicity (eco-friendliness) and relative widespread availability (Odeku, 2005; Emeje et al., 2009; Nep and Conway, 2010; Ogaji and Okafor, 2011).

Plant gums are organic substances obtained as an exudation from fruits, trunk or branches of the trees spontaneously or after mechanical injury of the plant by incision of the bark or after the removal of the branch or after invasion by bacteria or fungi (Ahmed et al., 2009). Gums are complex polysaccharides which consist of high molecular weight polymeric compounds composed mainly of carbon, hydrogen, oxygen and nitrogen. They are capable of displaying colloidal properties in an appropriate solvent or swelling agent. According to Ahmad et al. (1994), most plant gums are polyelectrolytes, which is a class of polymers that bears a large number of ionizable groups on the main chain. Gums have numerous applications in several industries. For example, Albizia zygia and some Albizia lebbeck gums have been found to be useful as natural emulsifiers for food and pharmaceuticals (Mhinzi, 2002). According to de Paula et al. (2001), Albizia lebbeck gum exudate is also used as a substitute for Arabic gum in the metallurgical industries. Guar and some other gums have a number of applications in the mining and mineral processing industry (Ma and Pawlik, 2007). Irvingia gabonensis(Aubry-Lecomte ex O'Rorke) Baill, is a specie of tree that grow in West Africa. It produces a fruit that is similar to mangoes. People use the flesh and seeds of this fruit to make food and medicines. This fruit is very high in fiber, protein, and healthy fats (FAO 19932007).

The aim of the study is to determine the physicochemical and rheological properties of the plant gums from Irvingia gabonensis and compare the properties of the plant gums with Gum Arabic (Acacia senegal) which is one of the most commercially used plant gum.

\section{MATERIALS AND METHODS}

Crude Irvingia gabonensis gum was obtained as dried exudates from their parent trees. The gum was collected from the plant species by tapping (Smith and Montgomery, 1959). 


\section{Special Conference Edition November, 2017}

The procedure adapted for the purification of the gum was that of Femi - Oyewo et al., (2004). The pH and conductivity were determined according to the method of ASTM D3838-80.

The solubility of the gum was determined in cold, hot distilled water and ethanol. One gram $(1.0 \mathrm{~g})$ of the gum sample was added to $50 \mathrm{ml}$ each of the above mentioned solvents and left overnight. $25 \mathrm{ml}$ of the clear supernatants were taken in small pre-weighted evaporating dishes and heated to dryness over a digital thermostatic water bath. The weights of the residue with reference to the volume of the solutions were determined using a digital top loading balance (Model.XP-3000) and expressed as the percentage solubility of the gums in the solvents (Carter 2005).

Density measurements were carried out at $25^{\circ} \mathrm{C}$ using $25 \mathrm{~cm}^{3}$ density bottle. For the gum sample, a density of the aqueous solution was determined. Clean, dry density bottle was weighed (MO) on a digital top loading balance. The bottle was then filled with distilled water and weighed again (M1). Another weighing (M2) was done with the gum solution replacing distilled water in the density bottle. Relative density of gum solution was evaluated as:

$\mathrm{RD}=\underline{M_{2}}-\underline{M}_{0}(1)$

A Cannon Ubbelohde capillary viscometer (Cannon Instruments, model 1-71) was used. The gum solution was prepared by dispersing $1.0 \mathrm{~g}$ of the gum sample in $100 \mathrm{ml}$ of distilled water at room temperature. Twelve milliter $(12 \mathrm{ml})$ of the prepared sample was transferred into the viscometer. The viscometer was immersed in a thermostated viscometer bath, calibrated using a thermometer with a precision of $0.01 \mathrm{~K}$, to equilibrate for 10 minutes at $30{ }^{\circ} \mathrm{C}$. After equilibration, the sample was pumped into the bulb and allowed to flow past the lower mark on the viscometer under the influence gravitational force. The time of flow of the sample from the upper through the lower mark was noted and recorded in seconds. Triplicate measurements were made and the average values reported. Serial dilution was performed in situ to obtain other concentrations $(0.8,0.6, \quad 0.4$ and $0.2 \% \mathrm{w} / \mathrm{v})$. The relative viscosity was calculated using the equation:

$$
\eta_{(\eta) \text { relativeviscosity }}=\frac{T-T_{O}}{T_{O}}
$$

Where $T$ is the flow time of the gum mucilage in seconds and $T_{o}$ is the flow time of solvent (water) in seconds. $[\eta]$ is defined by the following relationships:

$$
\begin{aligned}
& \text { Relative viscosity: } \eta_{\text {rel }}=\frac{\eta_{\text {solution }}}{\eta_{\text {solvent }}} \\
& \text { Specific viscosity: } \eta_{s p}=\eta_{\text {rel }}-1 \\
& \text { Intrinsic/reduce viscosity: } \eta_{\text {red }}=\frac{\eta_{s p}}{C}
\end{aligned}
$$

Effects of Temperature, Concentration and Added Electrolytes on Viscosities of Gums The viscometer was used as described above. One percent $(1 \% \mathrm{w} / \mathrm{v})$ concentrations of each of the gums were prepared and their viscosities at temperature range $30-70{ }^{\circ} \mathrm{C}$ were determined. Also, another $1 \% \mathrm{w} / \mathrm{v}$ concentration of the gums at different concentrations of $\mathrm{KCl}, \mathrm{AlCl}_{3}$, $\mathrm{KBr}$ i.e., $0.2,0.4,0.6,0.8$ and $1.0 \mathrm{M}$ of the electrolytes solutions were prepared. Viscosity values of the gums at different concentrations of electrolytes were measured.

\section{RESULTS AND DISCUSSION}

\section{Physicochemical Properties}

The result of physicochemical parameters of irviginia gabonensis (IG) and Acacia Senegal (AS) gum exudates are shown in Fig. 1.0 and Table 1.0 The AS gum was found with higher solubility values $(A S=9.8$ and $I G=6.6)$ in water compare to IG gum, while IG gum has the highest UV maximum absorption and density values.

The results obtained revealed that the colour of IG and AS gums is brownish and yellow respectively. Also, the gums displayed odourless and tasteless characteristics. Upon purification, the yields for the gums were relatively high ranging from $86.60 \%$ for IG gum to $90.50 \%$ for AS gum. At the measured room temperature $\left(30^{\circ} \mathrm{C}\right)$ the $\mathrm{pH}$ of IG and $\mathrm{AS}$ gums was 5.42 and 5.01 respectively. This indicates that the gums are acidic and the degree of acidity tends to vary from one gum to another. All the gums studied were found to be soluble in water but insoluble in ethanol. This also indicates that the gums are ionic. As a rule, ionic compounds are soluble in water and other solvents that have high dielectric constant. The solubility of IG and AS gums in water was found to increase with increase in temperature. The observed increase in solubility with temperature indicate that the heat given off in dissolving the gum is less than the heat required to break the gum apart. The net dissolution reaction is endothermic (energy required). Therefore, addition of more heat facilitated the dissolution of the gum by providing energy to break bonds within the gums. 
Special Conference Edition November, 2017

On the other hand, chloroform and acetone are non-polar solvents and as expected, non-polar compounds are soluble in non-polar solvent and vice versa. It has been found that the solubility of some ionic compounds vary in this manner the measured conductivities of IG and AS gums (123.6 and185 $\mu \mathrm{S} / \mathrm{cm}$ respectively) were relatively high and comparable with those of ionic compounds (Rouxel, 2011). However, the two gums were found to exhibit low salinity values indicating that the conductivity of the gums may not be primarily due to the presence of ions but due to movement of charges within the colloidal system (Zadeh et al., 2007).

Measured values of turbidity for IG and AS gums were 79 and 25 FAU respectively. These results indicate that the ability of the studied gums to scatter light follows the order AS>IG. It is interesting to note that AS gum is slightly turbid because of weak light scattering while IG is highly turbid because of strong light scattering. Turbidity is related to light scattering according to Dror et al., (2006) and according to Pablyana et al., (2007), increasing values of turbidity implies higher amount of insoluble contents in the polysaccharides while Yadav et al., (2008) also related turbidity as a property that increases with increasing emulsifying property of a polymer. The density of the gums indicates that the aggregate of particles or mass per volume of IG gum is higher than that of the AS gum. with temperature due to changes in properties and structure of liquid water. An increase in temperature can increase the degree of solutesolvent interaction resulting in an increase in solubility.

The high $\lambda \max$ noticed in the gums may be as a result of high degree of conjugation which absorb light in the UV or visible regions of the electromagnetic spectrum. $\lambda \max$ of IG gum is $366 \mathrm{~nm}$ that of AS gum is $200 \mathrm{~nm}$. The increase in IG gum which maybe as a result of the presence of high percentage composition of conjugated organic compounds, it may also be as the result of interaction of polymeric substance present in the IG gum, thereby increasing its ability to absorb more UV electromagnetic spectrum.

Effects of Temperature, Concentration and Addition of Electrolyte on the Viscosity of the Gum Solutions

Effects of temperature on the viscosity of the gums are shown in Figs. 1.0 and 2.0. The viscosity values were found to decrease with increase in temperature. Increases in concentration of the gums were also found to increase the viscosity of the gums as shown in Figs. 3.0, 4.0 and 5.0. Addition of electrolytes such as $\mathrm{KCl}, \mathrm{KBr}$ and $\mathrm{AlCl}_{3}$ were found to increase the viscosity of the gums solution as shown in Figs. 6.0, 7.0 and 8.0.

Table 1.0. Physicochemical parameters of Irviginia gabonensis(IG)and Acacia Senegal(AS) gum

\begin{tabular}{lll}
\hline Physicochemical parameters & Irvingia gabonensis(IG) Gum & Acacia senegal(AS )Gum \\
\hline Colour & Brownish & Yellow \\
Odour & Odourless & Odourless \\
Taste & Tasteless & Tasteless \\
$\begin{array}{l}\text { Solubility @ } 30^{\circ} \mathrm{C}, \mathrm{N}=3 \\
\text { (a) Water }(\%)\end{array}$ & $6.6 \pm 0.1$ & $9.8 \pm 0.0$ \\
(b) Ethanol (\%) & 0 & 0 \\
pH@27 $\mathrm{C}$ C, N=3 & $5.42 \pm 0.01$ & $5.01 \pm 0.01$ \\
UV Max. Absorption (nm), N=3 & 366 & 200 \\
Turbidity (FAU), N=3 & $79 \pm 1$ & $25 \pm 0$ \\
Conductivity $(\mu \mathrm{s} / \mathrm{cm}), \mathrm{N}=3$ & $123.6 \pm 1.4$ & $185.0 \pm 0.0$ \\
Salinity (psu), N=3 & $0.2 \pm 0.1$ & $0.1 \pm 0.0$ \\
Density , N=3 & $1.36 \pm 0.00$ & $1.35 \pm 0.00$ \\
Total dissolve solid $(\mathrm{mg} / \mathrm{l}), \mathrm{N}=3$ & $92.0 \pm 0.2$ & $87.0 \pm 0.1$ \\
\hline
\end{tabular}

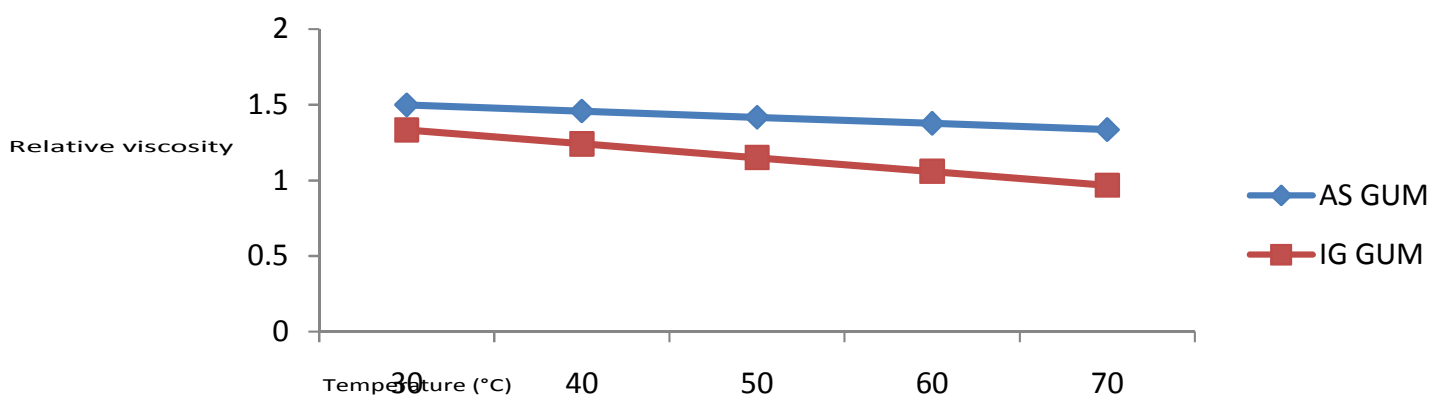

Fig. 1: Effect of temperature on relative viscosity of the gums 


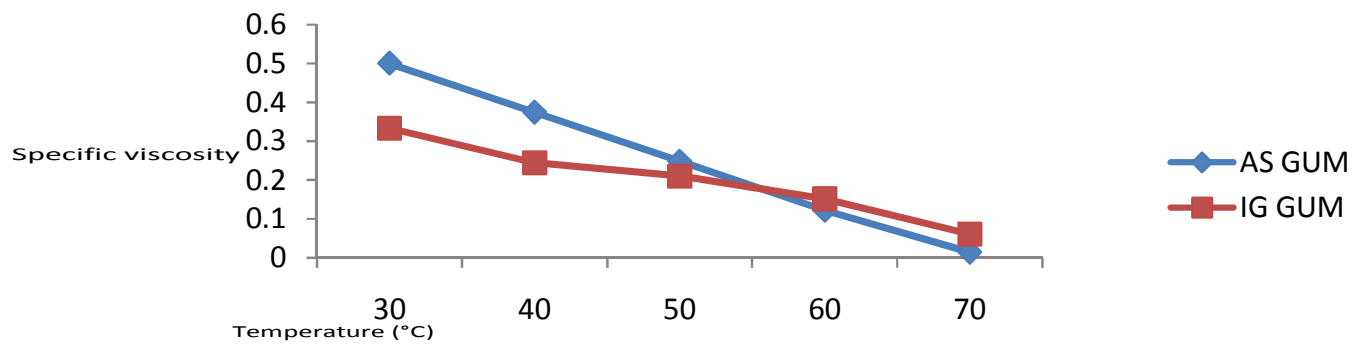

Fig. 2: Effect of temperature on specific viscosity of the gums

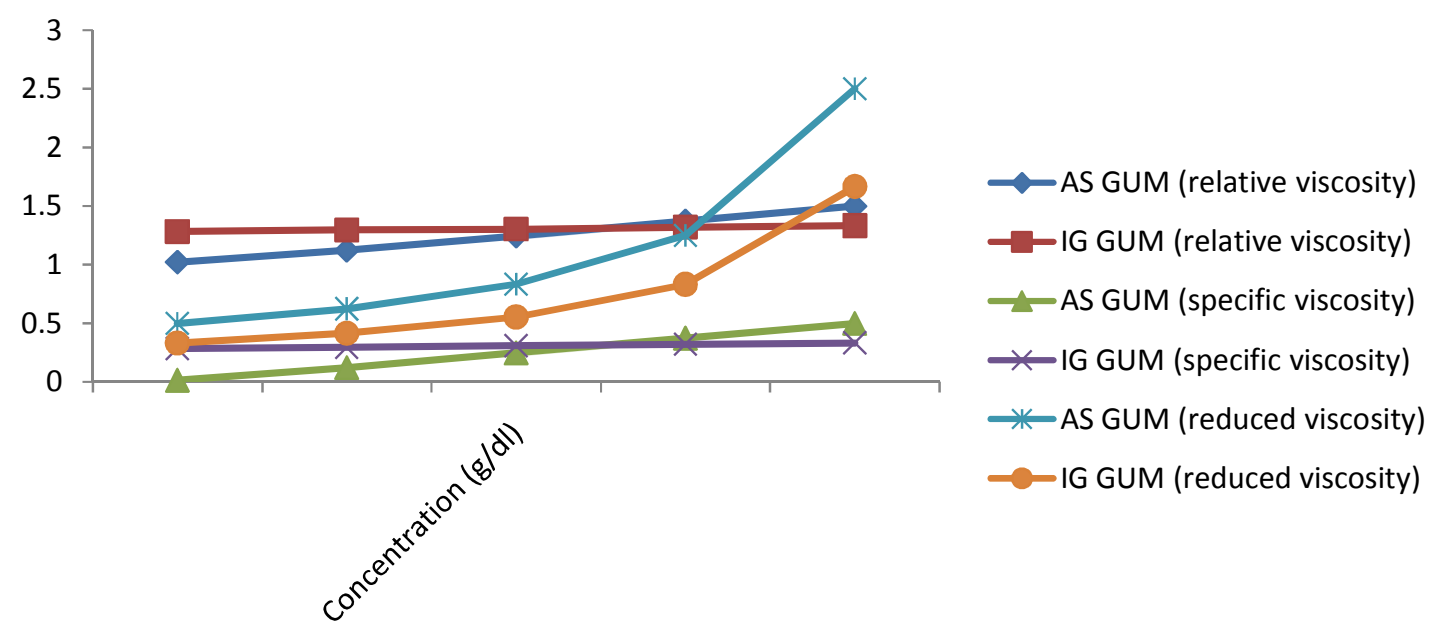

Fig. 3: Effect of concentration on the viscosity of the gum solutions.

Effects of Increase in Temperature and Concentration on Viscosity

Figs. 1 and 2 present plots for the variation of relative and specific viscosity with variable temperature. It is evident from the Figs. 1 and 2 that the relative and specific viscosity of the gums tends to decreases with increase in temperature of the gum but it increases with increase in concentration of the gum (Figs. 3 and 40). The trend observed for the gums can be explained as follows. At low temperature values, the electrostatic repulsions between the gum particles are low but at higher temperature the repulsive force is high thereby reducing the viscosity. But on the other hand the increase in viscosity due to increase in concentration of the gums is as the result of increase in association but at lower concentration there is decrease in association due to possible formation of hydrogen bonds, Van der Waals and other weak forces. Therefore increase in concentration of the pure gums led to an increase in their specific viscosity, with Acacia senegal gum (AS gum) having the highest value of specific viscosity value and Irvingia gabonensis gum (IG gum) being the least.
Effects of Added Electrolytes on the Viscosity Exudate gums are acid polysaccharides containing various metal ions as neutralized cations. It has been found that due to their metal content, exudate gums behave as polyelectrolyte (de Paula et al., 2001). Therefore, the solution viscosity of the gums can be affected by the addition of other electrolytes. In this study, effects of $\mathrm{KCl}, \mathrm{KBr}$ and $\mathrm{AlCl}_{3}$ on the viscosity of IG, and AS gums were investigated. Figs. 6.0, 7.0 and 8.0 show the variation of viscosity in IG and AS gums with concentrations in the presence of $0.1 \mathrm{M}$ of $\mathrm{KCl}, \mathrm{KBr}$ and $\mathrm{AlCl}_{3}$. The electrolytes $(\mathrm{KCl}, \mathrm{KBr}$ and $\mathrm{AlCl}_{3}$ ) were found to increase the viscosities of IG and AS gums such that the magnitude of increase tend to increase with increase in the charge of the ions (i.e. $\mathrm{Al}^{3+}>\mathrm{K}^{+}$). The order observed for the effect of $\mathrm{K}^{+}$and $\mathrm{Al}^{3+}$ on viscosity of IG and $A S$ gums can be explained as follows. The $\mathrm{KCl}$ and $\mathrm{AlCl}_{3}$ increases the viscosity of IG and AS gums because the electrolytes $\left(\mathrm{KCl}\right.$ and $\left.\mathrm{AlCl}_{3}\right)$ has the steric capability of gelling the gums compared to $\mathrm{KBr}$. This capability is less or absent in $\mathrm{KBr}$ hence, $\mathrm{KCl}$ exhibited the greatest potential to increase the viscosity of the gums, followed by $\mathrm{AlCl}_{3}$. 
Special Conference Edition November, 2017

The decrease found in AS gums in $\mathrm{KBr}$ according to de Paula et al. (2001) can be attributed to existence of less intermolecular interaction due to the screening charges and contraction of the macromolecule in the presence of counter ion. It has been found that aluminium has a tendency of establishing strong interaction with macromolecules through intermolecular crosslinking effect. On the other hand, the strength of intermolecular cross-linking effect is lower in potassium $\left(\mathrm{K}^{+}\right)$than in aluminium $\left(\mathrm{Al}^{3+}\right)$. This explains the order observed for decrease in viscosity in terms of AS gums. Ahmad et al. (1994) found that in dilute solution, the turbidity of dilute polyelectrolyte increases with increase in the charge of the ions present. In this work, the variation of the viscosities of the studied gums with increasing charge can therefore be attributed to their effect on turbidity. It is also significant to state that the affinity between each of the studied gums and their counter ions depends on the ratio (charge/ionic ratio). Generally, ions with higher charge will have a stronger affinity for the molecular chain of the gum. The charge to ionic radius ratio of $\mathrm{K}^{+}$and $\mathrm{Al}^{3+}$ are 0.66 and 4.41 respectively hence the expected order for the interaction of the studied gums with metal ions is $\mathrm{Al}^{3+}>\mathrm{K}^{+}$, which is in agreement with the findings of this study.

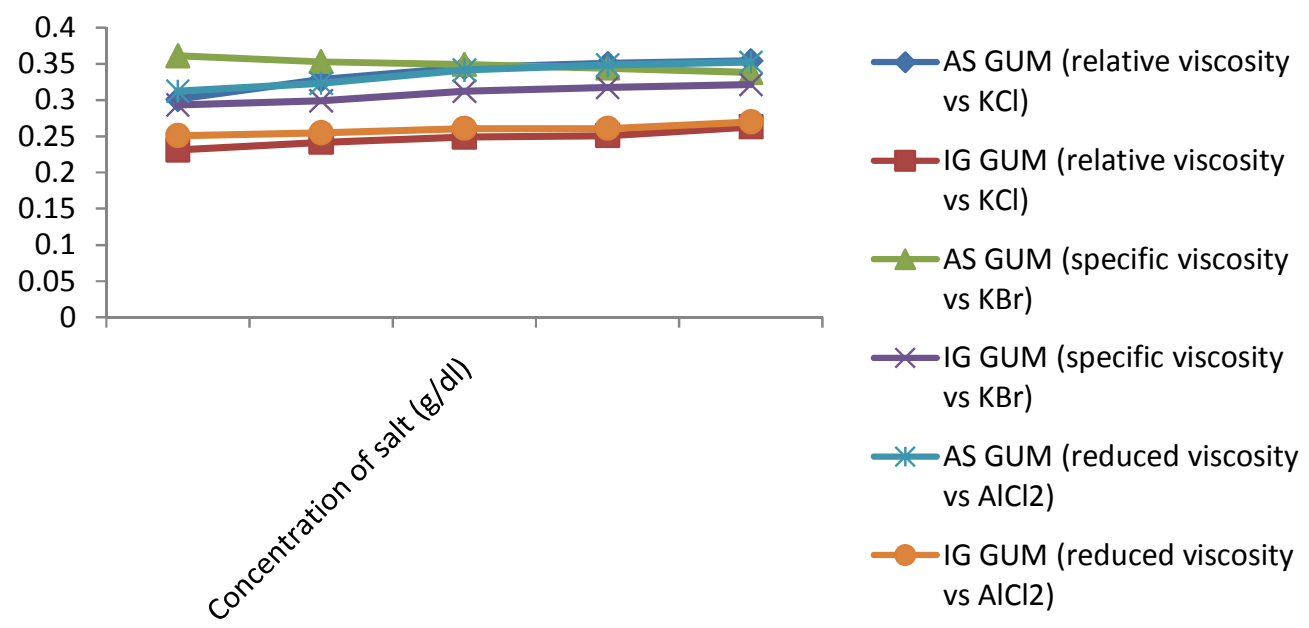

Fig. 3: Effect of Electrolytes on the viscosities of the gums solution

In all the studied gums, it was found that $\mathrm{KCl}$ and $\mathrm{AlCl}_{3}$ increased the viscosity of the gum solution by their tendency to form a porous framework, they have the ability to trap many organic compounds in its so-called clathrates (the organic guest) molecules are held in channels formed by interpenetrating helices.

\section{CONCLUSION}

Irvingia gabonensis gum occurs as brownish in colour. The gum mucilage has a bland taste, odourless and mild acidic with a pH of 5.4 at

\section{REFERENCES}

Ahmad, N., Saeed, A., Ahad, K. and Khan, M. S. (1994). Effect of counter ion charge on the viscosity of dilue polyelectrolyte solutions. Journal of Chemical Society of Pakistan16(4): 235-239.

Ahmad, N., Saeed, A., Ahad, K. and Khan, M. S. (1994). Efect of temperature on the viscosity of dilute polyelectrolyte solutions. Journal of Chemical Society of Pakistan 16(2): 91-94.

Ahmed, S. E., Mohamed, B. E. and Karamalla, K. A. (2009). Analytical studies on the gum
$300 \mathrm{~K}$. It is soluble in water and practically insoluble in ethanol, acetone and chloroform. The effects of electrolytes on the viscosity of the Irvingia gabonensis gum solutions are found to be in agreement with what is found in Acacia Senegal gum, hence it can be recommended for used as food additive, pharmaceutical and industrial applications,

Acknowledgement

I wish to acknowledge the contribution and supervision of this research from the beginning to the end by Professor E.B Agbaji and Professor N.O Eddy of the Department of Chemistry Ahmadu Bello University Zaria.

exudates from Anogeissus leocarpus. Pakistan Journal of Nutrition 8(6): 782-786.

Carter SJ (2005). Tutorial Pharmacy: Solution. Great Britain: Pitman Press. pp. 15-18.

De Paula, R. C. M., Santana, S. A. and Rodrigues, J. F. (2001).Composition and rheological properties of Albizia lebbeckgum exudate. Carbohydrate Polymers 44: 133-139.

Dror, Y., Cohen, Y. and Yerushalmi-Rozen, R. (2006).Structure of Gum arabic in aqueous solution. Journal of Polymer Science Part B. 44:3265-3271. 
Special Conference Edition November, 2017

Emeje, M. Isimi, C., Byrn, S., Fortunak, J.Kunle, O. and Ofoefule, S. (2009). Extraction and physicochemical characterization of a new polysaccharide obtained from the Fresh Fruits of Abelmoschus esculentus..Iranian Journal of Pharmaceutical Research, 10(2): 80-90.

Femi-Oyewo, M. N., Adedokun, M. O. and Olusoga, T. O. (2003). Evaluation of the suspending properties of Albizia zygiagum on sulphadimidine suspension. Tropical journal of pharmaceutical resources3(1): 279-284.

Liu, Q., Zhang, Y., and Laskowski, J. S. (2000). "The adsorption of polysaccharides onto mineral surfaces: An acid/base interaction." Int. J. Miner. Process., 60(34), 229-245.

Laskowski, J. S., Liu, Q., and O'Connor, C. T. (2007). "Current understanding of the mechanism of polysaccharide adsorption at the mineral/aqueous solution interface." Int.J. Miner. Process., 84(1-4), 59-68.

Laskowski, J. S., and Liu, Q. (2007)."Adsorption of Polysaccharides on Minerals."Taylor \& Francis, 649-668.

Ma, X. and Pawlik, M. (2007) Intrinsic viscosities and Huggins constants of guar gum in alkali metal chloride solutions. Carbohydrate Polymers 70: 15-24.

Metallurgical Society of CIM, 3400 de Maisonneuve Blvd. West, Suite 1210, Montreal, QC H3Z 3B8, Canada, 227-236.

Mhinzi, G. S. (2002). Properties of gum exudates from selected Albizia species from Tanzania. Food Chemistry 77: 301-304.

Nalaskowski, J., Abdul, B., Du, H., and Miller, J. D. (2007). "Anisotropic character of talc surfaces as revealed by streaming potential measurements, atomic force microscopy, molecular dynamics simulations and contact angle measurements." 77-80.

Nep, E. I and Conway, B. R. (2010).Characterization of Grewia gum, a potential pharmaceutical excipient. Journal of Excipient and Food Chemistry 1(1): 3040.

Ngondi, Judith L; Oben, Julius E; Minka, Samuel R (2005). "The effect of Irvingia gabonensis seeds on body weight and blood lipids of obese subjects in Cameroon". Lipids in Health and Disease 4: 12. doi:10.1186/1476-511X-4-12. PMC 1168905.PMID 15916709.

Ngondi, Judith L; Etoundi, Blanche C; Nyangono, Christine B; Mbofung, Carl MF; Oben, Julius E
(2009). "IGOB131, a novel seed extract of the West African plant Irvingia gabonensis, significantly reduces body weight and improves metabolic parameters in overweight humans in a randomized double-blind placebo controlled investigation". Lipids in Health and Disease 8: 7. doi:10.1186/1476-511X-8-7. PMC 2651880.PMID 19254366.

Pablyana, L. R., Cunha, R., de Paula, C. M. and Feitosa, J. P. A. (2007).Purification of guar gum for Biological applications. International Journal of Biological Macromolecules 41: 324-331.

Rath, R. K., Subramanian, S., and Laskowski, J. S. (1997). "Adsorption of dextrin and guar gum onto talc. A comparative study." Langmuir, 13(23), 6260-6266.

Rath, R.K., Subramanian, S., Laskowski, J.S., 1999. Interactions of guar gum with hydrophobic solids. Proceedings of the Third UBC-McGill International Symposium b Polymers in Mineral Processing Q, pp. 185197.

Rouxel, T. (2011). Thermodynamics of viscous flow and elasticity of glass forming liquids in the glass transition range. The Journal of chemical physics 135:184501-184501.

Steenberg, E., 1982. The depression of the natural floatability of talc: the mechanism involved in the adsorption of organic reagents of high molecular mass. PhD thesis (Industrial Chemistry).Faculty of Science, University of Potchefstroom, Johannesburg, South Africa.

Steenberg, E., Harris, P.J., 1984. Adsorption of carboxymethyl cellulose, guar gum and starch onto talc, sulphides, oxides and salttype minerals. South African Journal of Chemistry 37, 85.

Subramanian, S., Laskowski, J., 1993.Adsorption of dextrin onto graphite. Langmuir 9, 5.

Wie, J., Fuerstenau, D., 1974. The effect of dextrin on the surface properties and the flotation of molybdenite. International Journal of Mineral Processing 1, 67.

Yadav, M. P., Parris, N., Johnson, D. B. and Hicks, K. B. (2008). Fractionation, characterization and study of the emulsifying properties of corn fibre gum. Journal of Agriculture and Food chemistry 56:4181-4187.

Zadeh, M.A., Zandi, K., Sartavi, K., Rastian, Z., Antiviral activity of Aloe vera against herpes simplex virus type 2: An in vitro study. African Journal Biotech.2007; 6: 1770-73. 